\title{
Utility of Healthcare System-Based Interventions in Improving the Uptake of Influenza Vaccination in Healthcare Workers at Long-Term Care Facilities: A Systematic Review
}

\author{
Angela Bechini 1 ${ }^{(D)}$, Chiara Lorini ${ }^{1}$ (D), Patrizio Zanobini 1,*(D), Francesco Mandò Tacconi ${ }^{2}$, \\ Sara Boccalini ${ }^{1}$ (D), Maddalena Grazzini ${ }^{3}$, Paolo Bonanni ${ }^{1}$ (D) and Guglielmo Bonaccorsi $^{1}$ (D) \\ 1 Department of Health Sciences, University of Florence, Viale GB Morgagni 48, 50134 Florence, Italy; \\ angela.bechini@unifi.it (A.B.); chiara.lorini@unifi.it (C.L.); sara.boccalini@unifi.it (S.B.); \\ paolo.bonanni@unifi.it (P.B.); guglielmo.bonaccorsi@unifi.it (G.B.) \\ 2 Nuovo Ospedale delle Apuane, North-West Tuscany LHU, Via Enrico Mattei, 21, 54100 Massa, Italy; \\ francesco.mandotacconi@uslnordovest.toscana.it \\ 3 Careggi, University Hospital, Largo G. Alessandro Brambilla, 3, 50134 Florence, Italy; \\ grazzinim@aou-careggi.toscana.it \\ * Correspondence: patriziozanobini@gmail.com; Tel.: +39-366-343-5179
}

Received: 28 February 2020; Accepted: 3 April 2020; Published: 5 April 2020

\begin{abstract}
Healthcare workers (HCWs) in long-term care facilities (LTCFs) can represent a source of influenza infection for the elderly. While flu vaccination coverage (VC) is satisfactory in the elderly, HCWs are less likely to be vaccinated. There is no definitive evidence on which types of healthcare system-based interventions at LTCFs would be more useful in improving the vaccination uptake among HCWs. We performed a systematic review in different databases (Pubmed, Cochrane Database of Systematic Reviews, Health Evidence, Web of Science, Cinahl) to provide a synthesis of the available studies on this topic. Among the 1177 articles screened by their titles and abstracts, 27 were included in this review. Most of the studies reported multiple interventions addressed to improve access to vaccination, eliminate individual barriers, or introduce policy interventions. As expected, mandatory vaccinations seem to be the most useful intervention to increase the vaccination uptake in HCWs. However, our study suggests that better results in the vaccination uptake in HCWs were obtained by combining interventions in different areas. Educational campaigns alone could not have an impact on vaccination coverage. LTCFs represent an ideal setting to perform preventive multi-approach interventions for the epidemiological transition toward aging and chronicity.
\end{abstract}

Keywords: healthcare professionals; healthcare workers (HCWs); influenza vaccination; long-term care facilities (LTCFs); nursing homes; staff; utility; vaccination coverage

\section{Introduction}

The burden of disease due to seasonal influenza is high in terms of morbidity and mortality (250,000-500,000 deaths worldwide) every year. Recent estimates suggest that up to 650,000 people die of respiratory diseases linked with seasonal flu every year, with most deaths occurring among people aged over 75 years [1-3].

The risk groups for influenza include subjects having an increased risk of exposure to influenza viruses as well as those having a high risk of developing severe disease and complications with a high risk of dying if not hospitalized. Healthcare workers (HCWs) belong to the first group, as they are more exposed to influenza than the general population, while elderly people belong to the second 
group. Generally, the elderly population is at high risk of complications due to respiratory infections. This is shown by the high mortality rates in this population during the influenza seasons around the world [4-7].

Vaccination is the main public health intervention to prevent influenza. It can prevent significant annual morbidity and mortality, especially in healthcare settings [8,9]. Internationally, all available vaccines for the control of seasonal influenza are safe and effective, and their appropriated use to confer the highest protection to each individual [10-12]. Moreover, influenza immunization is a priority in countries where an aging population is on the rise [13-18], even though the effectiveness of influenza vaccination of HCWs in preventing influenza in the elderly is not conclusive [19].

HCWs working at long-term care facilities (LTCFs) are in close contact with the elderly and can represent a source of infection for those fragile subjects. Several studies show that healthcare professionals work at those facilities even after contracting the flu [8,20-26].

Actually, influenza outbreaks in LTCFs are very common as they occur in as many as $50 \%$ of such facilities each year [27].

According to some authors, there is a positive correlation among increasing vaccination rates in HCWs and a decrease in influenza diseases in the elderly [28-35]. Salgado et al. have shown that improving the vaccine acceptance rate of clinicians can prevent nosocomial influenza [36] Moreover, it could be a cost-effective intervention $[37,38]$.

Nevertheless, while vaccination coverage rates are satisfactory in the elderly population at the hospital or healthcare settings, HCWs are less likely to be vaccinated, regardless of international recommendations $[4,39,40]$. Additionally, influenza vaccination coverage among healthcare personnel working in LTCFs is consistently lower than those working in all other healthcare settings (i.e. hospitals, ambulatory care, physician's office) [41,42]. Most European member states recommend influenza vaccinations for all HCWs, while some of them recommend vaccination only for some HCW categories (e.g., staff with close contact with patients, staff with no patient contact but contact with potentially contaminated material, or social care staff directly involved in frontline patient care) [41].

Even in the context of specific recommendations, the healthcare system is the cornerstone of vaccination promotion. Since "the health system consists of all organizations, people, and actions whose primary intent is to promote, restore, or maintain health" and "healthcare providers are institutions or individuals providing healthcare services," LTCFs are part of the healthcare system [43].

Interventions based on the healthcare system involve the use of coordinated activities that are implemented primarily in healthcare settings. Generally, these interventions require organizational changes by considering the healthcare system as a whole [44]. Moreover, changes in one part of a system is estimated to influence the other parts and, therefore, preventive interventions should focus on the entire process of patient care.

Healthcare system-based strategies may be included in the quality improvement of care and can foresee knowledge management (e.g., training of staff) and redesign of professional roles (e.g., lead professional for vaccination promotion) [45].

There is still no definitive evidence on which types of healthcare system-based interventions at LTCFs are more useful in improving the vaccination uptake among HCWs. Therefore, the aim of this systematic review was to provide a synthesis of the available studies regarding this topic.

\section{Materials and Methods}

\subsection{Search Strategy}

One of the authors conducted a database search in the following databanks: Pubmed, Cochrane Database of Systematic Reviews, Health Evidence, Web of Science, and Cinahl. The last search was completed on 31 January, 2020. No temporal limits were applied. Only articles in written English were included. 
Research manuscripts reporting large datasets that are deposited in a publicly available database should specify where the data have been deposited and provide the relevant accession numbers. If the accession numbers have not yet been obtained at the time of submission, please state that they will be provided during review. They must be provided prior to publication.

Intervening studies involving animals or humans and other studies requiring ethical approval must list the authority that provided approval and the corresponding ethical approval code. We followed the search strategy in keeping with the PICO scheme-Cochrane Handbook for Systematic Reviews of Interventions [46]—-which is summarized in the following question: "Are healthcare system-based interventions useful in increasing the uptake of influenza vaccination in healthcare workers in long-term facilities?"

The search strategy followed on Pubmed and Web of Science was prepared by selecting groups of keywords for each part of the PICO scheme. Each group was combined with others through the Boolean operator AND. For Cinhal, Health evidence, and Cochrane library, a simplified search strategy was performed (Box S1). All electronic database search results were combined in Endnote and duplicate records were removed.

Only primary studies, systematic reviews, and meta-analyses were considered. Among them, we selected those which were considered relevant in terms of interventions, populations, and outcomes defined in the research question.

Three reviewers independently screened all the titles, abstracts, and full texts to assess the studies that met the selection criteria. In case of any discrepancies or disagreements during the selection phase, a fourth researcher was consulted.

The Preferred Reporting Items for Systematic Reviews and Meta-Analyses (PRISMA) flow diagram guidance was used to display studies that were identified by the database search and met the inclusion and exclusion criteria [47].

\subsection{Definition of HCWs, LTCFs, Type of Intervention}

HCWs were defined as the workforce in charge of a healthcare facility who directly (doctors and nurses) or indirectly (ancillary or technical staff, pharmacists, cleaners ... ) delivers healthcare services to the residents.

There is no internationally recognized standard definition for LTCFs. According to European Centre for Disease Prevention and Control (ECDC), the term 'long-term care services' refers to the organization and delivery of a broad range of services and assistance to people who are limited in their ability to function independently on a daily basis. Generally, they respond to both health and social needs [48].

In our study, LTCFs were defined as any residential organization that houses older adults or elderly individuals with the assistance of medical and nursing staff.

For the inclusion in the final list of selected papers, healthcare system-based interventions can be grouped into one of the following three types of approaches/areas.

(a) Interventions aimed at enhancing access to vaccination services (expanded access in healthcare settings, reduced or free vaccination costs, on-site vaccination, etc.),

(b) Interventions to eliminate individual barriers (reminder and recall systems, education, incentives, etc.),

(c) Policy/leadership interventions directed to mandate vaccination coverage in HCWs (mandatory vaccination as a condition for employment, severe restrictions for unvaccinated HCWs, declination forms, etc.).

The investigated outcome was an increasing rate of influenza vaccination in HCWs in any dose, preparation, or time schedule compared to other kinds of intervention or no intervention. We analysed the effects of interventions on both immediate and long-term changes in influenza vaccination rates. 
We excluded studies reporting only serological outcomes if they did not include or report either an intervention to increase vaccination rates or an outcome of vaccination rates.

\subsection{Quality Assessment}

Papers were assessed using the Effective Public Health Practice Project's (EPHPP) quality assessment tool for quantitative studies [49]. Studies of weak quality were excluded from the narrative data synthesis.

\section{Results}

\subsection{General Description of the Collected Studies}

The literature search and selection of articles has been described in Figure 1. Among the 1177 articles screened by their titles and abstracts, 27 papers were included in the current study. They were all primary studies that met the inclusion criteria of the PICO model and, therefore, was included in our review.

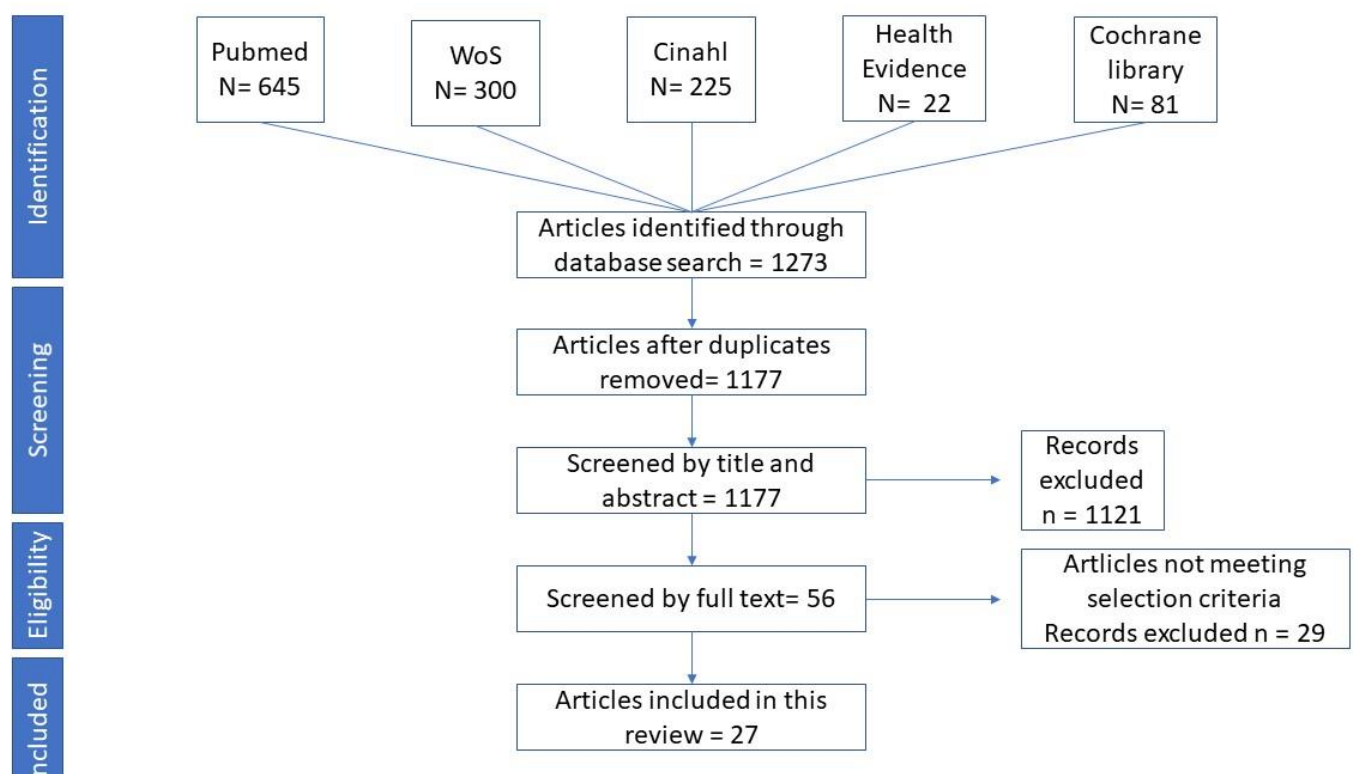

Figure 1. Preferred Reporting Items for Systematic Reviews and Meta-Analyses (PRISMA) flow diagram.

Table 1 shows the list of the healthcare system-based interventions performed in the studies included in the final synthesis. They were classified into three areas, as previously described in the 'Materials and Methods' section. 
Table 1. Synthesis of the interventions performed in the studies, by area of intervention.

\begin{tabular}{|c|c|c|}
\hline Area & Interventions & Code \\
\hline \multirow{7}{*}{$\begin{array}{l}\text { Interventions to improve the } \\
\text { access to vaccination }\end{array}$} & Vaccination available at work, in any locations & $1 \mathrm{a}$ \\
\hline & Offering vaccine during new hire orientation & $1 b$ \\
\hline & Temporal access (vaccination offered during day and night shifts) & 1c \\
\hline & Continuing to provide vaccines throughout the season & $1 \mathrm{~d}$ \\
\hline & Holding vaccination kick-off events & $1 \mathrm{e}$ \\
\hline & Free vaccination offered & 1f \\
\hline & Provide vaccination at reduced cost & $1 \mathrm{~g}$ \\
\hline \multirow{8}{*}{$\begin{array}{l}\text { Interventions to eliminate } \\
\text { individual barriers } \\
\text { (attitudes/opinions) }\end{array}$} & Identification of the individual and context barriers to vaccination & $2 \mathrm{a}$ \\
\hline & Improve vaccination confidence for directors & $2 b$ \\
\hline & Providing in-service educational seminars or educational sessions for staff & $2 \mathrm{c}$ \\
\hline & Displaying educational written materials (posters, leaflets, ... ) & $2 d$ \\
\hline & Offering incentives (treats, raffle tickets) to vaccinated health care workers & $2 \mathrm{e}$ \\
\hline & Providing additional education to staff who declined the vaccine & $2 \mathrm{f}$ \\
\hline & Individual counselling sessions & $2 \mathrm{~g}$ \\
\hline & Facilities provide reminders to staff to be immunized & $2 \mathrm{~h}$ \\
\hline \multirow{14}{*}{$\begin{array}{l}\text { Policy/leadership interventions } \\
\text { directed to lead to vaccination }\end{array}$} & Introduce a policy on immunization & $3 a$ \\
\hline & Mandatory vaccination policy & $3 b$ \\
\hline & Facility recommends influenza immunization for staff & $3 c$ \\
\hline & Requiring completion of declining forms & $3 d$ \\
\hline & Consider vaccination rate as a target for quality improvement & $3 e$ \\
\hline & $\begin{array}{l}\text { Identified lead persons to arrange for vaccination sessions and vaccination } \\
\text { promotion }\end{array}$ & $3 f$ \\
\hline & Facilitation support by experts & $3 g$ \\
\hline & Discussing proposed policies and goals with researchers & $3 \mathrm{~h}$ \\
\hline & Continual performance feedback and shared learning & $3 \mathbf{j}$ \\
\hline & Communicating with staff about vaccination goal & $3 \mathrm{k}$ \\
\hline & Sharing vaccination rates with staff & 31 \\
\hline & Communicating with staff about new policies on immunization & $3 \mathrm{~m}$ \\
\hline & Requiring vaccine receipt or masking throughout the season & $3 n$ \\
\hline & Discussing vaccination policy during new hire orientation & 30 \\
\hline
\end{tabular}

Tables S1 and S2 report the synthesis of the included studies. Seven were randomized controlled trials [50-56], six were pre-post surveys [57-62], one assessed the vaccination rate trend in accordance with the types of interventions [63], 11 were cross sectional studies [64-74], and two were interrupted time series studies $[75,76]$. The majority $(52 \%)$ of the selected studies were performed in the USA, which was followed by Europe (33\%), Canada (11\%), and Australia (4\%). The number of facilities involved varied between one to 2303 facilities. Regarding the target population considered, 15 studies (56\%) engaged not only health professionals, but all the people working at the facility.

With the EPHPP quality assessment tool [49], seven out of the 27 studies included in the current review were assessed as works of 'strong' quality [50-56], five papers of 'moderate' quality [58,63,72, $74,75]$, and the remaining 15 works as 'weak' quality [56,59-62,64-71,73,76]. Results of the application of the EPHPP quality assessment tool are reported in Tables S1 and S2. Generally, most of the studies reported multiple interventions addressed to improve access to vaccination, to eliminate individual barriers, or to introduce policy interventions aimed at improving vaccination uptakes.

In 26 studies, the adopted interventions were associated with a higher vaccination rate or an increased level of vaccine uptake. In just one study [65], no significant association was found between the financing of influenza vaccination for HCWs and/or a vaccination promotion campaign and an 
increase in the vaccination rate. Two studies reported the effect of the interventions proposed as part of the quality improvement process [61,76].

\subsection{Type of Interventions}

Most of the studies examined the effect of multiple interventions with simultaneous components belonging to multiple areas presented in Table 1. Seventeen studies investigated the effect of interventions to improve access to vaccination. Twelve studies evaluated the effect of the availability of vaccination on worksites (1a) $[51,53,55,57,63,67-71,74,76]$, and four of the vaccinations were offered during day and night shifts (1b) $[53,69,71,76]$ while four of the organized vaccination events (1c) $[54,55$, $62,63]$, and eleven of the vaccinations were offered free of charge or at a reduced cost (1d) $[51,52,57,60$, 64-68,73,74].

Twenty-three studies evaluated the effect of interventions to eliminate individual barriers (attitudes/opinions). Three studies evaluated the effect of "identification of the individual and context barriers to vaccination" (2a), [54,61,76] 21 of "providing in-service educational or seminars educational sessions or counselling sessions for staff" (2b) [51,52,54-56,58-63,65-67,69,71,73-76], six of "displaying educational written materials" (2c) [51-53,55,56,70], two of "offering incentives to vaccinated healthcare workers" (2d) [61,64], and three "facilities providing reminders to staff to be immunized" (2e) [67,70,75].

Eighteen studies examined policy/leadership interventions that lead to vaccination. Five "have a policy on immunization" (3a) [53,60,67,69,72], five have a "mandatory vaccination policy" (3b) [57, $63,64,71,74]$, three have "facilities recommending influenza immunization for staff" (3c) $[51,67,70]$, three "require completion of declination forms" (3d) [61,66,75], five "identify lead personnel to arrange for vaccination sessions and vaccination promotion" (3e) $[51,53,58,59,74]$, one "facilitates support by experts" (3f) [50], five "document vaccination status of staff and share feedback and goals" (3g) $[59,60,67,71,76]$, one arranges "patient restriction for sick employees" (3h) [64], two consider the "vaccination rate as a target for quality improvement" (3j) [61,76], and three refer to "leadership involvement" (3k) [59,61,76].

\subsection{Studies with Interventions Related to One Area}

Five studies evaluated the effect of interventions related to only one area $[50,56,58,68,72]$. Two [56, 58] evaluated the effect of interventions to eliminate individual barriers, while two [50,72] more evaluated the effect of policy interventions and one [68] more evaluated the effect of interventions to increase access to vaccination. One study [50] was of strong quality and evaluated the effect of 'facilitation support by experts' demonstrating an increase in the vaccination rate (at the facility-level) in the intervention group, from $65 \%$ at baseline (2008-2009) to $87 \%$ (2011-2012). On the contrary, in the control group, the vaccination rate ranged from $72-92 \%$ at baseline (2008-2009) to $67-80 \%$ (2011-2012). Two studies [58,72] were of moderate quality. The first study [58] assessed the impact of a training programme. Facilities participating in a single collaborative training programme improved the immunization rates modestly from $39.2 \%$ (2002) to $50.1 \%$ (2003), while facilities not participating saw decreases in such rates. The second study [72] found that the vaccination rate was $22 \%$ among care homes without a policy on staff influenza immunization, compared with $42 \%$ among care homes that did have such a policy $(p=0.01)$. However, it was not possible to establish what kind of policies were in use.

\subsection{Studies with Interventions Related to Two Areas}

Ten studies $[52,54,55,57,59,61,62,65,73,75]$ evaluated the effect of interventions related to two areas taken together. Seven studies $[52,54,55,62,65,73,75]$ applied a combination of better access to vaccination and reduction of individual barriers. One [59] performed leadership interventions and reduction of individual barriers, and two $[57,61]$ combined easy access and leadership interventions. Three were assessed of strong quality [52,54,57]. In the first study [52], free vaccination was offered 
by general practitioners to both intervention and control groups. However, the intervention group was visited by a public health nurse, who performed an educational campaign while disseminating promotional materials and informing staff where they could obtain vaccination free of charge. No significant difference in vaccination rates was found between the intervention group and the control group. One study [54] investigated the effect of an educational campaign and Vaccine Day. Combining both was the most effective strategy for increasing the vaccine coverage (53\% in the intervention group compared to $27 \%$ in the control group). Vaccine Day alone was also effective ( $46 \%$ coverage), while the educational campaign alone was not effective in improving coverage levels ( $34 \%$ coverage). The third study [57] found an increase in the vaccination rates at residential care facilities after vaccination was provided at no charge through onsite clinics and the introduction of a mandatory vaccination policy from $57 \%$ for the $2011 / 2012$ flu season to $75 \%$ for the 2012/2013 flu season (difference in the proportion regarding 2011/2012 $=0.18,95 \%$ CI: $0.18-0.19, p<0.001$ ). One study of moderate quality [75] found that nursing homes with formal education programmes and easy access to vaccination have a $10 \%$ higher staff vaccination rate $(p<0.001)$, and higher odds of achieving a $60 \%$ vaccination rate $(\mathrm{OR}=1.77$, $p=0.01)$.

\subsection{Studies with Interventions Related to Three Areas}

Ten studies $[51,53,60,64,66,67,69-71,76]$ assessed the impact on vaccination rates of interventions related to three areas taken together. However, only two studies $[51,53]$ were of strong quality. The first [51] evaluate the effect of a vaccination campaign, which consisted of free vaccination on site, educational media, reminder for staff, and monitoring progresses. Vaccination rates increased from $27.6 \%$ at baseline to $33.7 \%$ after the intervention while, in the control group, vaccination rates decreased from $24.2 \%$ to $22.9 \%$. The second study [53] evaluated the introduction of policy for influenza vaccination. It was performed by training lead nurses in each of the intervention homes to promote the influenza vaccine to staff and to arrange for three vaccination sessions within the homes, including at least one session during a night shift, to maximize the uptake. In 2003-2004, the vaccination coverage in full-time staff was $48.2 \%$ at intervention homes and $5.9 \%$ at control homes, while the uptake rates were $43.2 \%$ and $3.5 \%$, respectively, from $2004-2005$.

Two studies [63,74] of moderate quality examined the effect of all three areas of interventions. The first [63] reported that the vaccination rate among HCWs in the study period (2013-2017) ranged from $90-98.4 \%$ for HCWs working where employer vaccination was a requirement to be employed, from $67.3-80.4 \%$ for HCWs working where on-site vaccination was offered, from $54.1-83.0 \%$ for HCWs working where on-site vaccination was provided for only one day, and from $58.5-71.7 \%$ for HCWs working where other vaccination promotions were performed. The vaccination coverage was the lowest (38.6-44.3\%) among healthcare providers working in locations where employers do not require vaccination, provide on-site vaccination at no cost, or promote vaccination. The second [74] found that influenza vaccination was independently associated with an employer vaccination requirement (prevalence ratio $(\mathrm{PR})(95 \%$ confidence interval $)=1.28(1.11,1.47))$, which offered free onsite vaccination $(\mathrm{PR}=1.20(1.04,1.39))$, and employers publicizing the vaccination coverage level to employees $(P R=1.24(1.09,1.41))$. No significant association was found between being informed of the risks and benefits of vaccination and being vaccinated. However, vaccination was most highly associated with a combination of three or more workplace interventions.

\section{Discussion}

\subsection{General Issue}

The influenza vaccination uptake among HCWs at LTCFs is a relevant issue due to its potential risk of transmission to fragile residents and the associated mortality and morbidity. Moreover, the tendency to remain absent during influenza outbreaks can affect the quality of care $[77,78]$. Although the World Health Organization (WHO) states that 'influenza vaccination should be offered to all staff 
who will potentially have contact with LTCF residents' [79], the influenza vaccination uptake among the LTCF staff varies between countries and facilities, with vaccination coverages generally lower than those of the residents and those of the staff working in hospital settings [77,80,81]. According to WHO guidelines, many interventions should be performed to improve influenza vaccination acceptance and coverage in this setting, but it is still hard to establish which of them has the higher impact on the vaccination uptake.

\subsection{Main Considerations about the Results}

According to our selection criteria, 27 studies published from 1993-2019 addressed the research question. This scientific production highlights the relative lack of research studies performed in this setting, even though the included studies describe interventions conducted in many different countries. No study was performed in a developing country. The applied interventions can greatly vary and be classified, as previously reported, in those aimed at improving access to vaccination, those dedicated to eliminating individual barriers, and those focused on introducing policy interventions directed to mandate vaccination. Most of the studies reported multiple interventions, while the others describe the effect of a single intervention or of several of them. In 26 out of 27 studies, an increase in the influenza vaccination coverage or a positive association between intervention and vaccination was observed with a large variability. The results of this review suggest that healthcare system-based interventions improve the influenza vaccination uptake among HCWs at LTCFs, which generally results in an increase of vaccination adherence, particularly when vaccine administration is performed after the assessment of specific needs and barriers. However, according to the state of the art assessed in this review, vaccine uptake in healthcare workers of LTCFs shows a miscellaneous pattern, reflecting the same heterogeneity of the different organization models of each healthcare structure in each country. The level of vaccination varied greatly in the published studies and it is not possible to clearly identify which interventions are more useful in increasing the uptake of influenza vaccination. However, there are some exceptions. As expected, the most relevant single intervention is the introduction of a mandatory vaccination policy. Two studies of moderate quality [42,74] after the implementation of mandatory vaccination report the highest vaccination coverages (ranging between 90\% and 98\%) among all studies considered in our review. In contrast, educational interventions are not always useful. In two studies of strong quality [52,54], educational campaign failed to increase vaccination uptake in HCWs. One study of moderate quality [74] also did not find any significant association between being informed of the risks and benefits of vaccination and being vaccinated. Our study suggests that better results in the vaccination uptake in HCWs were obtained by combining more interventions in different areas. Two studies [54,74] analyse the effect of both single interventions and a combination of them. In both studies, a combination of multiple interventions was more effective than any single intervention outside of employer vaccination requirements at increasing vaccination coverage. In fact, educational campaigns related to Vaccine Day is an effective strategy to increase the vaccine coverage among healthcare workers of LTCFs, especially when lead nurses involved in the programme are trained to promote the influenza vaccination for the staff. Educational campaigns can also be effective when they are performed after evaluating the barriers to influenza vaccination among healthcare workers.

LTCFs cover different types of healthcare settings, varying for context, residents, and staff characteristics, services provided to the residents, and size. They can also differ among countries and even within the same country, primarily due to distinctive regulations at the national or regional level and to peculiar needs of each geographical area. In fact, long-term care policies, including those regarding residential facilities, differ considerably between countries, due to nation's structure and organization, history, culture, or even economic performance [82-86]. This diversity partially explains the variety in the vaccination uptake among the staff in the studies included in this review (from $0 \%-100 \%$ ), the interventions that have been implemented, and the effect of the interventions in improving vaccination. For example, Russel [71] assesses the effect of mandatory vaccination, 
which is not legally enforceable in all countries. Most researchers working on the topic report interventions based on national or regional policies aimed at increasing vaccine uptake. In some cases, they have conducted studies or implemented surveillance activities because of national or regional recommendations $[52,53,57,59,61,63-67,69,71-76]$. Although these policies have the same aim (i.e., to improve $\mathrm{HCWs}^{\prime}$ vaccination uptake), the implemented interventions differed. They are tailored to specific barriers and needs only in three cases $[54,56,60]$.

Two of the included studies reported the effect of interventions proposed as part of the quality improvement process $[62,76]$. They were both conducted in the USA, where the quality of care at LTCFs has been a topic of great interest for a longer time than in other countries $[87,88]$. The quality of care in LTCFs has attracted plenty of interest in recent years and it is now one of the most challenging issues for policymakers. In this setting, poor quality of care represents an issue of public concern and discussions are taking place to address this topic $[82,89,90]$. Due to the impact of influenza outbreaks on the health of residents and the organization of the healthcare provided, the influenza vaccination rate among staff should be considered a patient safety issue, which is to be monitored using a specific indicator of quality of care [91], as it has already been done for the vaccination rate among residents [92,93].

Lastly, HCWs and healthcare organizations should promote strategies and educational interventions to increase the awareness of knowledge, attitudes, and behaviours toward flu vaccination and the adoption of preventive measures in such populations and settings [94,95].

\subsection{Strengths and Weaknesses}

Based on our knowledge, this is the first systematic review of the utility of healthcare system-based interventions in improving the influenza vaccination uptake in HCWs at LTCFs. Moreover, the results summarize a great number of different interventions currently described in the primary studies performed in this setting. About half of the included research papers have a study design that considers both intervention and control groups. This type of study is the best to test the etiologic hypothesis [96], even though only seven studies were evaluated as 'strong' for their quality. Thirteen studies have a cross-sectional design or are interrupted time-series analysis. Because of the nature of the study design, it is not possible to work out whether an association between exposure (proposed interventions) and outcome (vaccination rate) underlies a cause-effect relationship [97]. Moreover, as a limitation of our review, the studies retrieved included many types of different interventions that do not allow a conclusive quantitative synthesis of the utility of each intervention.

Lastly, the publication bias may have led to an overestimation of the effect of healthcare system-based interventions. We found only one study [52] that did not report an increase in vaccination coverage after implementing an intervention. A recent review [98] has shown that there is strong evidence of an association between significant results and publication. Specifically, studies that report positive or significant results are more likely to be published and outcomes that are statistically significant have higher odds of being fully reported.

\section{Conclusions}

According to the results of this review, healthcare system-based interventions can be useful to improve the influenza vaccination uptake among HCWs at LTCFs. The heterogeneity of LTCFs, and the fragmentation of the interventions proposed in the studies prevent the identification of the most effective strategies in improving the vaccination rate. As expected, mandatory vaccination seems to be the most useful intervention to increase the vaccination uptake in HCWs. Our study suggests that better results in the vaccination uptake in HCWs were obtained by combining more interventions in different areas. Educational campaigns alone could not have an impact on vaccination coverage. Further studies, concerning long-term intervention programmes, will be necessary to ascertain the effectiveness of preventive measures at LTCFs.

Supplementary Materials: The following are available online at http://www.mdpi.com/2076-393X/8/2/165/s1. Box S1: Search strings used for each database (Pubmed; Web of science; Cinhal; Health evidence; Cochrane library). 
Table S1: Synthesis of the studies involving intervention and control groups and Quality Assessment (EPHPP) of each study. Table S2: Synthesis of the studies not involving intervention and control groups and Quality Assessment (EPHPP) of each study.

Author Contributions: Conceptualization, A.B., C.L., P.Z., F.M.T., S.B., M.G., and G.B. Methodology, P.Z. Formal analysis, P.Z., C.L., and A.B. Investigation, A.B., P.Z., F.M.T., and C.L. Data curation, A.B., P.Z., F.M.T., S.B., M.G., and C.L. Writing-original draft preparation, A.B., P.Z., C.L., P.B., and G.B. Writing-review and editing, A.B., C.L., P.Z., M.G., and G.B. Supervision, G.B. All authors have read and agreed to the published version of the manuscript.

Funding: This research received no external funding.

Conflicts of Interest: The authors declare no conflict of interest.

\section{References}

1. Iuliano, A.D.; Roguski, K.M.; Chang, H.H.; Muscatello, D.J.; Palekar, R.; Tempia, S.; Cohen, C.; Gran, J.M.; Schanzer, D.; Cowling, B.J.; et al. Global Seasonal Influenza-associated Mortality Collaborator Network. Estimates of global seasonal influenza-associated respiratory mortality: A modelling study. Lancet 2018, 391, 1285-1300. [CrossRef]

2. WHO. Influenza (Seasonal) Fact Sheet. Available online: http://www.who.int/mediacentre/factsheets/fs211/en/ (accessed on 4 February 2019).

3. Redlberger-Fritz, M.; Aberle, J.H.; Popow-Kraupp, T.; Kundi, M. Attributable deaths due to influenza: A comparative study of seasonal and pandemic influenza. Eur. J. Epidemiol. 2012, 27, 567-575. [CrossRef] [PubMed]

4. Vaccines against influenza WHO position paper-November 2012. Wkly. Epidemiol. Rec. 2012, 87, 461-476.

5. Michiels, B.; Govaerts, F.; Remmen, R.; Vermeire, E.; Coenen, S. A systematic review of the evidence on the effectiveness and risks of inactivated influenza vaccines in different target groups. Vaccine 2011, 29, 9159-9170. [CrossRef] [PubMed]

6. Vellozzi, C.; Burwen, D.R.; Dobardzic, A.; Ball, R.; Walton, K.; Haber, P. Safety of trivalent inactivated influenza vaccines in adults: Background for pandemic influenza vaccine safety monitoring. Vaccine 2009, 27, 2114-2120. [CrossRef] [PubMed]

7. Kuster, S.P.; Shah, P.S.; Coleman, B.L.; Lam, P.P.; Tong, A.; Wormsbecker, A.; McGeer, A. Incidence of influenza in healthy adults and healthcare workers: A systematic review and meta-analysis. PLoS ONE 2011, 6, e26239. [CrossRef]

8. Salgado, C.D.; Farr, B.M.; Hall, K.K.; Hayden, F.G. Influenza in the acute hospital setting. Lancet Infect. Dis. 2002, 2, 145-155. [CrossRef]

9. Bridges, C.B.; Kuehnert, M.J.; Hall, C.B. Transmission of influenza: Implications for control in health care settings. Clin. Infect. Dis. 2003, 37, 1094-1101.

10. Bonanni, P.; Boccalini, S.; Zanobini, P.; Dakka, N.; Lorini, C.; Santomauro, F.; Bechini, A. The appropriateness of the use of influenza vaccines: Recommendations from the latest seasons in Italy. Hum. Vaccines Immunother. 2018, 14, 699-705. [CrossRef]

11. Public Health England Sets Country Rules for Effective Flu Prevention: An Example to Follow for Italian Regions. Available online: https://www.bmj.com/content/360/bmj.k602/rr (accessed on 4 April 2020).

12. Boccalini, S.; Tacconi, F.M.; Lai, P.L.; Bechini, A.; Bonanni, P.; Panatto, D. Appropriateness and preferential use of different seasonal influenza vaccines: A pilot study on the opinion of vaccinating physicians in Italy. Vaccine 2019, 37, 915-918. [CrossRef]

13. Bonanni, P.; Bonaccorsi, G.; Lorini, C.; Santomauro, F.; Tiscione, E.; Boccalini, S.; Bechini, A. Focusing on the implementation of 21st century vaccines for adults. Vaccine 2018, 36, 5358-5365. [CrossRef]

14. Bridges, C.B.; Thompson, W.W.; Meltzer, M.I.; Reeve, G.R.; Talamonti, W.J.; Cox, N.J.; Lilac, H.A.; Hall, H.; Klimov, A.; Fukuda, K. Effectiveness and cost-benefit of influenza vaccination of healthy working adults: A randomized controlled trial. JAMA 2000, 284, 1655-1663. [CrossRef]

15. UN Population Division. World Population Prospects 2019. Available online: https://population.un.org/wpp/ (accessed on 4 February 2019).

16. Rivetti, D.; Jefferson, T.; Thomas, R.; Rudin, M.; Rivetti, A.; Di Pietrantonj, C.; Demicheli, V. Vaccines for preventing influenza in the elderly. Cochrane Database Syst. Rev. 2006, 3, CD004876. 
17. Demicheli, V.; Jefferson, T.; Di Pietrantonj, C.; Ferroni, E.; Thorning, S.; Thomas, R.E.; Rivetti, A. Vaccines for preventing influenza in the elderly. Cochrane Database Syst. Rev. 2018, 2, CD004876. [CrossRef]

18. Bonanni, P.; Boccalini, S.; Bechini, A. The expected impact of new vaccines and vaccination policies. J. Public Health 2008, 16, 253-259. [CrossRef]

19. Thomas, R.E.; Jefferson, T.; Lasserson, T.J. Influenza vaccination for healthcare workers who care for people aged 60 or older living in long-term care institutions. Cochrane Database Syst. Rev. 2016, 6, CD005187. [CrossRef]

20. Ridgway, J.P.; Bartlett, A.H.; Garcia-Houchins, S.; Cariño, S.; Enriquez, A.; Marrs, R.; Perez, C.; Shah, M.; Guenette, C.; Mosakowski, S.; et al. Influenza among afebrile and vaccinated healthcare workers. Clin. Infect. Dis. 2015, 60, 1591-1595. [CrossRef] [PubMed]

21. Taylor, G.; Mitchell, R.; McGeer, A.; Frenette, C.; Suh, K.N.; Wong, A.; Katz, K.; Wilkinson, K.; Amihod, B.; Gravel, D.; et al. Healthcare-associated influenza in Canadian hospitals from 2006 to 2012. Infect. Control Hosp. Epidemiol. 2014, 35, 169-175. [CrossRef] [PubMed]

22. Prevention strategies for seasonal influenza in healthcare settings. Available online: https://www.cdc.gov/ flu/professionals/infectioncontrol/healthcaresettings.htm (accessed on 4 February 2019).

23. Nguyen-Van-Tam, J.; Granfield, R.; Pearson, J.; Fleming, D.; Keating, N. Do influenza epidemics affect patterns of sickness absence among British hospital staff? Infect. Control Hosp. Epidemiol. 1999, 20, 691-694. [CrossRef] [PubMed]

24. Yassi, A.; McGill, M.; Holton, D.; Nicolle, L. Morbidity, cost and role of health care worker transmission in an influenza outbreak in a tertiary care hospital. Can. J. Infect. Dis. 1993, 4, 52-56. [CrossRef]

25. Hammond, G.W.; Cheang, M. Absenteeism among hospital staff during an influenza epidemic: Implications for immunoprophylaxis. Can. Med. Assoc. J. 1984, 131, 449-452. [PubMed]

26. Yassi, A.; Kettner, J.; Hammond, G.; Cheang, M.; McGill, M. Effectiveness and cost-benefit of an influenza vaccination program for health care workers. Can. J. Infect. Dis. 1991, 2, 101-108. [CrossRef] [PubMed]

27. Stevenson, C.G.; McArthur, M.A.; Naus, M.; Abraham, E.; McGeer, A.J. Prevention of influenza and pneumococcal pneumonia in Canadian long-term care facilities: How are we doing? CMAJ 2001, 164, 1413-1419.

28. Potter, J.; Stott, D.J.; Roberts, M.A.; Elder, A.G.; O’Donnell, B.; Knight, P.V.; Carman, W.F. Influenza vaccination of health care workers in long-term-care hospitals reduces the mortality of elderly patients. J. Infect. Dis. 1997, 175, 1-6. [CrossRef] [PubMed]

29. Nicholson, K.G. Should staff in long-stay hospitals for elderly patients be vaccinated against influenza? Lancet 2000, 355, 83-84. [CrossRef]

30. Nichol, K.L.; Grimm, M.B.; Peterson, D.C. Immunizations in long-term care facilities: Policies and practice. J. Am. Geriatr. Soc. 1996, 44, 349-355. [CrossRef]

31. Dille, J.H. A worksite influenza immunization program: Impact on lost work days, health care utilization, and health care spending. AAOHN J. 1999, 47, 301-309. [CrossRef]

32. Carman, W.F.; Elder, A.G.; Wallace, L.A.; McAulay, K.; Walker, A.; Murray, G.D.; Stott, D.J. Effects of influenza vaccination of health-care workers on mortality of elderly people in long-term care: A randomised controlled trial. Lancet 2000, 355, 93-97. [CrossRef]

33. Everts, R.J.; Hanger, H.C.; Jennings, L.C.; Hawkins, A.; Sainsbury, R. Outbreaks of influenza A among elderly hospital inpatients. N. Z. Med. J. 1996, 109, 272-274.

34. Adal, K.A.; Flowers, R.H.; Anglim, A.M.; Hayden, F.G.; Titus, M.G.; Coyner, B.J.; Farr, B.M. Prevention of nosocomial influenza. Infect. Control Hosp. Epidemiol. 1996, 17, 641-648. [CrossRef]

35. Pachucki, C.T.; Pappas, S.A.; Fuller, G.F.; Krause, S.L.; Lentino, J.R.; Schaaff, D.M. Influenza A among hospital personnel and patients. Implications for recognition, prevention, and control. Arch. Intern. Med. 1989, 149, 77-80. [CrossRef] [PubMed]

36. Salgado, C.D.; Giannetta, E.T.; Hayden, F.G.; Farr, B.M. Preventing nosocomial influenza by improving the vaccine acceptance rate of clinicians. Infect. Control Hosp. Epidemiol. 2004, 25, 923-928. [CrossRef] [PubMed]

37. Nichol, K. Cost-benefit analysis of a strategy to vaccinate healthy working adults against influenza. Arch. Intern. Med. 2001, 161, 749-759. [CrossRef] [PubMed]

38. Kumpulainen, V.; Makela, M. Influenza vaccination among healthy employees: A cost benefit analysis. Scand. J. Infect. Dis. 1997, 29, 181-185. [CrossRef] 
39. Advisory Committee on Immunization Practices; Centers for Disease Control and Prevention (CDC). Immunization of health-care personnel: Recommendations of the Advisory Committee on Immunization Practices (ACIP). MMWR Recomm. Rep. 2011, 60, 1-45.

40. Goldstein, A.O.; Kincade, J.E.; Gamble, G.; Bearman, R.S. Policies and practices for improving influenza immunization rates among healthcare workers. Infect. Control Hosp. Epidemiol. 2004, 25, 908-911. [CrossRef]

41. Seasonal Influenza Vaccination in Europe. Vaccination Recommendations and Coverage Rates in the EU Member States for Eight Influenza Seasons: 2007-2008 to 2014-2015. Stockholm: ECDC. 2017. Available online: https://ecdc.europa.eu/sites/portal/files/documents/influenza-vaccination-2007\%E2\%80\%932008-to2014\%E2\%80\%932015.pdf (accessed on 7 December 2010).

42. Black, C.L.; Yue, X.; Ball, S.W.; Fink, R.V.; de Perio, M.A.; Laney, A.S.; Williams, W.W.; Graitcer, S.B.; Fiebelkorn, A.P.; Lu, P.J.; et al. Influenza Vaccination Coverage Among Health Care Personnel—United States, 2017-2018 Influenza Season. MMWR Morb. Mortal. Wkly. Rep. 2018, 67, 1050-1054. [CrossRef]

43. WHO. Everybody's Business. Strengthening Health Systems to Improve Health Outcomes: WHO's Framework for Action; WHO: Geneva, Switzerland, 2007.

44. Community Preventive Services Task Force. Increasing Appropriate Vaccination: Health Care System-Based Interventions Implemented in Combination; US Department of Health and Human Services, the Community Preventive Services Task Force: Washington, DC, USA, 2015.

45. Wensing, M.; Wollersheim, H.; Grol, R. Organizational interventions to implement improvements in patient care: A structured review of reviews. Implement. Sci. 2016, 1, 2. [CrossRef]

46. Higgins, J.P.; Green, S. Cochrane Handbook for Systematic Reviews of Interventions. The Cochrane Collaboration. Version 5.1.0. March 2011. Available online: http://handbook-5-1.cochrane.org/ (accessed on 1 February 2019).

47. Moher, D.; Liberati, A.; Tetzlaff, J.; Altman, D.G.; The PRISMA Group. Preferred reporting items for systematic reviews and meta-analyses: The PRISMA statement. PLoS Med. 2009, 6, e1000097. [CrossRef]

48. European Centre for Disease Prevention and Control. Protocol for Point Prevalence Surveys of Healthcare-Associated Infections and Antimicrobial Use in European Long-Term Care Facilities-Version 2.1. Available online: https://www.ecdc.europa.eu/sites/portal/files/media/en/publications/Publications/HALT-3LTCF-PPS-Protocol-v2.1.pdf (accessed on 4 April 2020).

49. Effective Public Health Practice Project. Quality Assessment Tool for Quantitative Studies; 2009. Available online: https://www.ephpp.ca/PDF/Quality\%20Assessment\%20Tool_2010_2.pdf (accessed on 4 April 2020).

50. Chambers, L.W.; Crowe, L.; Lam, P.P.; MacDougall, D.; McNeil, S.; Roth, V.; Suh, K.; Dalzell, C.; Baker, D.; Ramsay, H.; et al. A new approach to improving healthcare personnel influenza immunization programs: A randomized controlled trial. PLOS ONE 2015, 10, e0118368. [CrossRef]

51. Borgey, F.; Henry, L.; Lebeltel, J.; Lescure, P.; Coutour, X.L.; Vabret, A.; Verdon, R.; Thibon, P. Effectiveness of an Intervention Campaign on Influenza Vaccination of Professionals in Nursing Homes: A Cluster-Randomized Controlled Trial. Vaccine 2019, 37, 1260-1265. [CrossRef]

52. Dey, P.; Halder, S.; Collins, S.; Benons, L.; Woodman, C. Promoting uptake of influenza vaccination among health care workers: A randomized controlled trial. J. Public Health Med. 2001, 23, 346-348. [CrossRef]

53. Hayward, A.C.; Harling, R.; Wetten, S.; Johnson, A.M.; Munro, S.; Smedley, J.; Murad, S.; Watson, J.M. Effectiveness of an influenza vaccine programme for care home staff to prevent death, morbidity, and health service use among residents: Cluster randomised controlled trial. BMJ 2006, 333, 1241. [CrossRef] [PubMed]

54. Kimura, A.C.; Nguyen, C.N.; Higa, J.I.; Hurwitz, E.L.; Vugia, D.J. The effectiveness of vaccine day and educational interventions on influenza vaccine coverage among health care workers at long-term care facilities. Am. J. Public Health 2007, 97, 684-690. [CrossRef] [PubMed]

55. Lemaitre, M.; Meret, T.; Rothan-Tondeur, M.; Belmin, J.; Lejonc, J.L.; Luquel, L.; Piette, F.; Salom, M.; Verny, M.; Vetel, J.M.; et al. Effect of influenza vaccination of nursing home staff on mortality of residents: A cluster-randomized trial. J. Am. Geriatr. Soc. 2009, 57, 1580-1586. [CrossRef] [PubMed]

56. Looijmans-van den Akker, I.; van Delden, J.J.; Verheij, T.J.; van der Sande, M.A.; van Essen, G.A.; Riphagen-Dalhuisen, J.; Hulscher, M.E.; Hak, E. Effects of a multi-faceted program to increase influenza vaccine uptake among health care workers in nursing homes: A cluster randomised controlled trial. Vaccine 2010, 28, 5086-5092. [CrossRef] [PubMed]

57. Ksienski, D.S. Mandatory seasonal influenza vaccination or masking of British Columbia health care workers: Year 1. Can. J. Public Health 2014, 105, e312-e316. [CrossRef] 
58. Nace, D.A.; Perera, S.; Handler, S.M.; Muder, R.; Hoffman, E.L. Increasing influenza and pneumococcal immunization rates in a nursing home network. J. Am. Med. Dir. Assoc. 2011, 12, 678-684. [CrossRef]

59. Nace, D.A.; Handler, S.M.; Hoffman, E.L.; Perera, S. Impact of the raising immunizations safely and effectively (RISE) program on healthcare worker influenza immunization rates in long term care settings. J. Am. Med. Dir. Assoc. 2012, 13, 806-810. [CrossRef]

60. Ofstead, C.L.; Amelang, M.R.; Wetzler, H.P.; Tan, L. Moving the needle on nursing staff influenza vaccination in long-term care: Results of an evidence-based intervention. Vaccine 2017, 35, 2390-2395. [CrossRef]

61. Sand, K.L.; Lynn, J.; Bardenheier, B.; Seow, H.; Nace, D.A. Increasing influenza immunization for long-term care facility staff using quality improvement. J. Am. Geriatr. Soc. 2007, 55, 1741-1747. [CrossRef] [PubMed]

62. Thomas, D.R.; Winsted, B.; Koontz, C. Improving neglected influenza vaccination among healthcare workers in long-term care. J. Am. Geriatr. Soc. 1993, 41, 928-930. [CrossRef] [PubMed]

63. Black, C.L.; Yue, X.; Ball, S.W.; Fink, R.; de Perio, M.A.; Laney, A.S.; Williams, W.W.; Lindley, M.C.; Graitcer, S.B.; Lu, P.J.; et al. Influenza Vaccination Coverage Among Health Care Personnel-United States, 2016-2017 Influenza Season. MMWR Morb. Mortal. Wkly. Rep. 2017, 66, 1009-1015. [CrossRef] [PubMed]

64. Apenteng, B.A.; Opoku, S.T. Employee influenza vaccination in residential care facilities. Am. J. Infect. Control 2014, 42, 294-299. [CrossRef]

65. Bentele, H.; Bergsaker, M.R.; Hauge, S.H.; Bjørnholt, J.V. Vaccination coverage for seasonal influenza among residents and health care workers in Norwegian nursing homes during the 2012/13 season, a cross-sectional study. BMC Public Health 2014, 14, 434. [CrossRef]

66. Borlaug, G.; Newman, A.; Pfister, J.; Davis, J.P. Factors that influenced rates of influenza vaccination among employees of Wisconsin acute care hospitals and nursing homes during the 2005-2006 influenza season. Infect. Control Hosp. Epidemiol. 2007, 28, 1398-1400. [CrossRef]

67. Halliday, L.; Thomson, J.A.; Roberts, L.; Bowen, S.; Mead, C. Influenza vaccination of staff in aged care facilities in the ACT: How can we improve the uptake of influenza vaccine? Aust. N. Z. J. Public Health 2003, 27, 70-75. [CrossRef]

68. Hauri, A.M.; Uphoff, H.; Gussmann, V.; Gawrich, S. Factors that affect influenza vaccine uptake among staff of long-term care facilities. Infect. Control Hosp. Epidemiol. 2006, 27, 638-641. [CrossRef]

69. Henry, B.; Naus, M.; Stirling, R. Impact of Influenza Vaccination Policies on Staff Coverage in Long-Term care Facilities; ScienceDirect: Amsterdam, The Netherlands, 2001; Volume 1219, pp. 671-675.

70. McArthur, M.A.; Simor, A.E.; Campbell, B.; McGeer, A. Influenza vaccination in long-term-care facilities: Structuring programs for success. Infect. Control Hosp. Epidemiol. 1999, 20, 499-503. [CrossRef]

71. Russell, M.L. Influenza vaccination in Alberta long-term care facilities. CMAJ 2001, 164, 1423-1427.

72. Shroufi, A.; Copping, J.; Musonda, P.; Vivancos, R.; Langden, V.; Armstrong, S.; Slack, R. Influenza vaccine uptake among staff in care homes in Nottinghamshire: A random cluster sample survey. Public Health 2009, 123, 645-649. [CrossRef] [PubMed]

73. Vaux, S.; Noël, D.; Fonteneau, L. Influenza vaccination coverage of healthcare workers and residents and their determinants in nursing homes for elderly people in France: A cross-sectional survey. BMC Public Health 2010, 10, 159. [CrossRef] [PubMed]

74. Yue, X.; Black, C.; Ball, S.; Donahue, S.; Perio, M.A.D.; Laney, A.S.; Greby, S. Workplace Interventions and Vaccination-Related Attitudes Associated With Influenza Vaccination Coverage Among Healthcare Personnel Working in Long-Term Care Facilities, 2015-2016 Influenza Season. J. Am. Med. Dir. Assoc. 2019, 20, 718-724. [CrossRef] [PubMed]

75. Campbell, L.J.; Li, Q.; Li, Y. Health care worker influenza vaccination in Oregon nursing homes: Correlates of facility characteristics. J. Am. Med. Dir. Assoc. 2014, 15, 847-848. [CrossRef]

76. Nace, D.A.; Hoffman, E.L.; Resnick, N.M.; Handler, S.M. Achieving and sustaining high rates of influenza immunization among long-term care staff. J. Am. Med. Dir. Assoc. 2007, 8, 128-133. [CrossRef]

77. Lansbury, L.E.; Brown Nguyen-Van-Tam, J.S. Influenza in long-term care facilities. Influenza Respir. Viruses 2017, 11, 356-366. [CrossRef]

78. Maltezou, H.C.; Poland, G.A. Immunization of Health-Care Providers: Necessity and Public Health Policies. Healthcare 2016, 4, 47. [CrossRef]

79. World Health Organization-Office for Europe. Prevention and Control of Outbreaks of Seasonal Influenza in Long-Term Care Facilities: A Review of the Evidence and Best-Practice Guidance; WHO: Geneva, Switzerland, 2017. 
80. Elias, C.; Fournier, A.; Vasiliu, A.; Beix, N.; Demillac, R.; Tillaut, H.; Guillois, Y.; Eyebe, S.; Mollo, B.; Crépey, P. Seasonal influenza vaccination coverage and its determinants among nursing homes personnel in western France. BMC Public Health 2017, 17, 634. [CrossRef]

81. Guthmann, J.P.; Fonteneau, L.; Ciotti, C.; Bouvet, E.; Pellissier, G.; Lévy-Bruhl, D.; Abiteboul, D. Vaccination coverage of health care personnel working in health care facilities in France: Results of a national survey, 2009. Vaccine 2012, 30, 4648-4654. [CrossRef]

82. The Organisation of Formal Long-Term Care for the Elderly: Results from the 21 European Country Studies in the ANCIEN Project. Available online: http://aei.pitt.edu/32969/1/RR_No_95_ANCIEN_Organisation_ of_Formal_LTC.pdf (accessed on 4 April 2020).

83. Leichsenring, K.; Billings, J.; Nies, H. Long-Term Care in Europe: Improving Policy and Practice; Springer: Berlin, Germany, 2013.

84. McGrail, K.M.; McGregor, M.J.; Cohen, M.; Tate, R.B.; Ronald, L.A. For-profit versus not-for-profit delivery of long-term care. CMAJ 2007, 176, 57-58. [CrossRef]

85. Eligibility and Inclusiveness of Long-Term Care Institutional Frameworks in Europe: A Cross-Country Comparison. Available online: http://dx.doi.org/10.2139/ssrn.2541246 (accessed on 4 April 2020).

86. The Development of Long-Term Care in Post-Socialist Member States of the EU. Available online: http: //dx.doi.org/10.2139/ssrn.2207861 (accessed on 4 April 2020).

87. Zimmerman, D.R. Improving nursing home quality of care through outcomes data: The MDS quality indicators. Int. J. Geriatr. Psychiatry 2003, 18, 250-257. [CrossRef] [PubMed]

88. Leichsenring, K. Achieving Quality Long-Term Care in Residential Facilities. Synthesis Report of the German Peer Review in Social Protection and Social Inclusion. Available online: https://ec.europa.eu/social/main.jsp? catId=1024\&langId=en\&newsId=1414\&moreDocuments=yes\&tableName=news (accessed on 4 April 2020).

89. Giorgio, L.D.; Filippini, M.; Masiero, G. Is higher nursing home quality more costly? Eur. J. Health Econ. 2016, 17, 1011-1026. [CrossRef] [PubMed]

90. OECD/European Commission. A Good Life in Old Age? Monitoring and Improving Quality in Long-Term Care: OECD Health Policy Studies; OECD Publishing: Paris, France, 2013.

91. Van Buynder, P.G.; Konrad, S.; Kersteins, F.; Preston, E.; Brown, P.D.; Keen, D.; Murray, N.J. Healthcare worker influenza immunization vaccinate or mask policy: Strategies for cost effective implementation and subsequent reductions in staff absenteeism due to illness. Vaccine 2015, 33, 1625-1628. [CrossRef] [PubMed]

92. Katz, P.R.; Karuza, J.; Lima, J.; Intrator, O. Nursing home medical staff organization: Correlates with quality indicators. J. Am. Med. Dir. Assoc. 2011, 12, 655-659. [CrossRef]

93. Bardenheier, B.H.; Wortley, P.; Ahmed, F.; Hales, C.; Shefer, A. Influenza immunization coverage among residents of long-term care facilities certified by CMS, 2005-2006: The newest MDs quality indicator. J. Am. Med. Dir. Assoc. 2010, 11, 59-69. [CrossRef]

94. Bonaccorsi, G.; Lorini, C.; Santomauro, F.; Guarducci, S.; Pellegrino, E.; Puggelli, F.; Balli, M.; Bonanni, P. Predictive factors associated with the acceptance of pandemic and seasonal influenza vaccination in health care workers and students in Tuscany, Central Italy. Hum. Vaccin. Immunother. 2013, 9, 2603-2612. [CrossRef]

95. Bonaccorsi, G.; Santomauro, F.; Porchia, B.R.; Niccolai, G.; Pellegrino, E.; Bonanni, P.; Lorini, C. Beliefs and Opinions of Health Care Workers and Students Regarding Influenza and Influenza Vaccination in Tuscany, Central Italy. Vaccines 2015, 3, 137-147. [CrossRef]

96. Rothman, K.J. Six persistent research misconceptions. J. Gen. Intern. Med. 2014, 29, 1060-1064. [CrossRef]

97. Grimes, D.A.; Schulz, K.F. Descriptive studies: What they can and cannot do. Lancet 2002, 359, $145-149$. [CrossRef]

98. Dwan, K.; Gamble, C.; Williamson, P.R.; Kirkham, J.J.; for the Reporting Bias Group. Systematic Review of the Empirical Evidence of Study Publication Bias and Outcome Reporting Bias-An Updated Review. PLoS ONE 2013, 8, e66844. [CrossRef]

(C) 2020 by the authors. Licensee MDPI, Basel, Switzerland. This article is an open access article distributed under the terms and conditions of the Creative Commons Attribution (CC BY) license (http://creativecommons.org/licenses/by/4.0/). 